\title{
Effect of Learning Communities on Student Attitudes and Corresponding Behaviors: A Mediated Test of Involvement Theory
}

\author{
Daniel Bonilla $^{1}$, Kimberly K. Buch ${ }^{1} \&$ Cindy Wolf Johnson ${ }^{1}$ \\ ${ }^{1}$ The University of North Carolina Charlotte, USA \\ Correspondence: Kimberly K. Buch, Department of Psychology, University of North Carolina Charlotte, Charlotte, \\ NC 28223, USA. Tel: 1-704-562-9772. E-mail:kkbuch@uncc.edu
}

Received: July 20, 2013

Accepted: July 28, 2013

Online Published: July 30, 2013

doi:10.5430/ijhe.v2n3p107

URL: http://dx.doi.org/10.5430/ijhe.v2n3p107

\begin{abstract}
Learning communities are small pre-selected student groups based on a common interest with a variety of goals related to student outcomes. Previous research has shown robust effects of learning community participation on student success outcomes, but little is known about the mechanisms which may mediate these effects. The current study analyzed two years of data on a large sample of first-year and transfer students using mediated regression techniques and logistic regression to explore the mechanism by which learning communities affect self reported student behaviors. Results showed that being in a learning community leads to positive academic and social attitudes which lead to increased academic and social behaviors respectively. Results shed light on the mechanism by which learning communities affect student outcomes.
\end{abstract}

Keywords: Learning communities, Involvement theory, Student success

\section{Introduction}

Many universities have a goal of improving key student outcomes such as retention, graduation rate, GPA, and probation rates. A variety of tools and interventions have been used with relative success (Taylor, 2004). One such intervention is the inclusion of students in learning communities aimed at increasing first year and new transfer student engagement through academic and social activities. Learning communities are small pre-selected student groups based on a common interest (Tinto, 2000) with a variety of goals related to student outcomes. Learning communities are usually focused on first year or new transfer students and students are often members for one year. Different types exist (see Lennings \& Ebber, 1999 for an expanded overview) however; the most popular are curriculum based programs where students are enrolled in courses together. Another popular characteristic is specific on-campus housing for learning community students. This further maximizes time shared among students within a learning community.

While learning communities are characterized in many ways, Tinto (2000) suggests that all learning communities have 1) shared knowledge, 2) shared knowing, and 3) shared responsibility. The communal aspect of these characteristics is important. Learning communities differentiate themselves from other student groups by the large amount of contact students have with each other and faculty within the learning community. According to Astin's involvement theory $(1985 ; 1993)$, students who are more engaged with each other, faculty, and the university at large will enjoy more positive academic and social outcomes. Learning communities are one way to improve student engagement. By placing students in the same housing, sharing blocked courses, and meeting for service-learning activities, students become more engaged with faculty, each other, and their education.

This is different from previous pedagogical theories in which students passively receive knowledge and skills to be used later (Astin, 1984). Rather, students are the central focus of the involvement model with the ability to increase (or decrease) the likelihood of their own success. However, students are not the only agents acting on their outcomes. Resources provided by the university can aid in increasing student engagement and act as a necessary, but not sufficient, component of student outcomes (Astin, 1985).

Learning communities offer a variety of resources to students that promote student engagement (Taylor, 2004; Zhao \& Kuh, 2004) and enhanced contact among students and faculty members (Buch \& Spaulding, 2008). They increase the quality and quantity of student engagement-a key component of involvement theory (Astin, 1984). Buch \& Spaulding (2008) argue that a good learning community should promote frequent and enhanced contact between 
students and faculty and cooperation among students to meet specified goals. Zhao \& Kuh (2004) emphasize the importance of shared responsibility, most often seen through cooperative group projects. Learning communities have been linked to a variety of positive outcomes and behaviors including higher GPA and retention rates than non-learning community peers (Buch \& Spaulding, 2008), social involvement and classroom engagement (Taylor, 2004), and general college student success (Astin, 1993). The positive outcomes and behaviors associated with being a member of a learning community can be split into two major categories- academic and social (Astin, 1993). Academic outcomes pertain to classic student success variables such as GPA, retention, graduation rate, and general scholastic excellence along with attitudes and behaviors about these. Social outcomes pertain to non-scholastic, yet important, personal attitudes and behaviors including a sense of belonging, social fit, and engaging in extra-curricular activities.

In summary, involvement theory provides a framework for improving student outcomes by acknowledging that 1) students have differing levels of engagement in their education and 2) their engagement levels are linked to positive attitudes and behaviors. Learning communities act to increase student engagement by increasing the quality and quantity of interaction among students and faculty. This increase in student engagement should lead to increased positive student attitudes. As will be explained in the next section, these increased positive attitudes should lead to increased positive corresponding behaviors.

\section{Attitudes and Behaviors}

The focus of involvement theory is student engagement (Astin, 1985). However, the theory has implications for attitude formation and behavioral changes. One approach is to consider attitudinal changes that act as antecedents to behavioral changes in students. These behavioral changes then lead to improved student outcomes. Scholars have suggested that relevant attitudes are the closest antecedents to behaviors (Judge, Thoresen, Bono, \& Patton, 2001). "Perhaps the most fundamental assumption underlying the attitude concept is the notion that attitudes in some way, guide, influence, direct, shape, or predict actual behavior" (Kraus, 1995 pg. 58).

Attitudes are constructs used to define evaluations individuals hold about any object, idea, theme, or construct. The target of an evaluation is called the attitude object. Attitudes are internal appraisals that are inferred from observable responses within the individual (Eagley \& Chaiken, 1993). These observable responses can be survey-based reports of one's attitudes. Kraus' meta-analytic study (1995) found a meaningfully significant mean correlation between attitudes and behaviors across 88 studies. Further, this relationship is strengthened when the specificity of the attitudes is increased. This supports the idea that specific attitudes can inform specific behaviors.

In the case of a learning community there are a variety of attitudes that are of interest. As Astin (1993) argues, these focal attitudes can be academic or social in nature. The literature on attitudes suggests that strong positive academic and social attitudes should lead to positive academic and social behaviors respectively (Eagley \& Chaiken, 1993). Indeed these two types of attitudes should differentially predict their corresponding behaviors. It makes no sense for social attitudes to inform scholastic behaviors and vice-versa. An example of a social attitude is perceived social fit within the university community. Its corresponding behavior can include engaging in social activities such as extracurricular student organizations and sports. An example of an academic attitude is perceived academic fit. Corresponding behaviors can include engaging in the classroom or taking more time to study with other students in the same class.

In a learning community, the attitudes of interest are often those that are shared as well. It is not enough for one student to agree that studying for a test is important. For a learning community to be considered effective all or most students must hold this attitude. Focusing on shared attitudes as an antecedent to group behavior is the basis of group climate research (Hofmann, Morgeson, \& Gerras, 2003; Zohar, 2000). In the example of safety climate, interventions are implemented with the intent of changing shared attitudes and perceptions about safety within organizations. The expected outcome is not only a change in attitudes, but a change in safety related behaviors as well (Hofmann, et al., 2003; Zohar \& Luria, 2005).

The same framework can be applied to students within a learning community compared to non-learning community students. Students within a learning community should have different attitudes from non-learning community students because learning community students are engaged in more student and faculty interaction. Logically, these students should report different and corresponding behaviors as well. Because the students within the learning community engage in shared experiences their attitudes ought to be shared as well. Thus, learning communities should serve to foster shared attitudes and behaviors among their members and to improve shared attitudes and behaviors beyond that of non-learning community students. 


\section{Hypotheses}

In support of previous research on learning communities we would expect generally positive student attitudes and self-reported behaviors associated with being a member of a learning community (Buch \& Spaulding, 2008; Taylor, 2004). In support of Astin's involvement theory (1985) and the literature on shared attitudes there should be a mediating effect of attitudes between learning communities and corresponding self-reported student behaviors.

Hypothesis 1: Students in learning communities will report significantly higher levels of academic and social attitudes and behaviors than students not in learning communities.

Hypothesis 2: Perceived social fit will act as a significant mediator in the relationship between being in a learning community and engaging in extracurricular student activities.

Hypothesis 3: Perceived academic fit will act as a significant mediator in the relationship between being in a learning community and spending time studying with students.

\section{Methods}

\subsection{Participants}

Participants were 9165 first year and transfer students at a large university in the southeastern United States who were invited to complete an academic and social engagement survey 8 weeks into their first fall semester on campus. 2,063 students $(22.5 \%$ response rate) completed the survey. The majority of respondents were female $(60 \%$, slightly higher than incoming new students), and the majority were Caucasian (68\%, close to average of incoming new students). Forty-seven percent of respondents were transfer students while $40 \%$ were first year students at the time of the survey (thirteen percent did not respond to this item). Nineteen percent of the students were enrolled in one of 16 learning communities available for new students at the university.

\subsection{Measures and Procedure}

The Evaluating Academic Success Effectively (EASE) survey was developed by the university's academic assessment team and has been administered to incoming first year and new transfer students since the fall of 2005 . The EASE survey asks participants a variety of questions concerning their level of engagement, student attitudes, use of campus services, student behaviors, educational background, and inclusion in first year programs. The EASE survey is administered to students via email and participation is completely voluntary. All data were anonymous and collection met all IRB standards for human study. A variety of items from the EASE survey were used for this study. The measures below were used specifically for the mediation analysis in hypotheses 2 and 3 .

Social Fit. This measure asks participants about their perceived level of social fit within the institution. It is made up of three items from the EASE survey. Items include I have friends at this institution; I feel this institution is a good fit for me socially and I feel lonely at this institution (reverse coded). Items were asked on a 5 point scale (strongly agree to strongly disagree) and internal reliability is adequate $(\alpha=.81)$.

Academic Fit. This is a one-item measure asking participants about their perceived level of academic fit within the institution. The item used is I feel this institution is a good fit for me academically. The item was asked on a 5 point scale (strongly agree to strongly disagree).

Student Club. This one-item measure asks participants about their extracurricular student activities. The item is Are you the member of at least one student club or organization this semester and is dichotomously coded as a yes or no.

Study with Other Students. This one-item measure asks participants about their studying behaviors with other students. The item is How often each seven day week do you study outside of class with other students and responses are on a 4 point scale (never to very often).

\section{Results}

Means, $t$-values, p-values, and sample sizes for learning community and non-learning community students on all variables are reported in Table 1. Results largely support hypothesis 1 that there are significant differences between learning community and non-learning community students in regard to academic and social attitudes and self-reported behaviors. Taken all together, learning community students appear to report more interaction with faculty members including receiving feedback on graded assignments and knowing of their advisor. Further, they appear to be more satisfied with their major of choice, feel a stronger academic fit and a stronger social fit, study more with other students, and engage in more extra-curricular activities than their non-learning community peers. 
Table 1. Differences in learning community and non-learning community students on all variables

\begin{tabular}{|c|c|c|c|c|c|}
\hline Variable & $\begin{array}{l}\text { Student } \\
\text { Category }\end{array}$ & Mean & $\mathrm{t}$ & $\mathrm{p}$-value & $\mathrm{N}$ \\
\hline \multirow{2}{*}{ Met with Faculty Member } & Non-LC & 1.81 & \multirow{2}{*}{-1.992} & \multirow{2}{*}{.046} & 1657 \\
\hline & $\mathrm{LC}$ & 1.9 & & & 392 \\
\hline \multirow{2}{*}{ Met with Advisor } & Non-LC & 0.76 & \multirow{2}{*}{-0.563} & \multirow{2}{*}{.574} & 1649 \\
\hline & $\mathrm{LC}$ & 0.79 & & & 392 \\
\hline \multirow{2}{*}{ Satisfied with Advisor } & Non-LC & 3.99 & \multirow{2}{*}{-1.448} & \multirow{2}{*}{.148} & 828 \\
\hline & $\mathrm{LC}$ & 4.09 & & & 203 \\
\hline \multirow{2}{*}{ Know Advisor } & Non-LC & 0.69 & \multirow{2}{*}{-4.471} & \multirow{2}{*}{.000} & 1647 \\
\hline & $\mathrm{LC}$ & 0.8 & & & 391 \\
\hline \multirow{2}{*}{ Received Feedback } & Non-LC & 3.93 & \multirow{2}{*}{-4.627} & \multirow{2}{*}{.000} & 1657 \\
\hline & $\mathrm{LC}$ & 4.33 & & & 392 \\
\hline \multirow{2}{*}{ Miss Class } & Non-LC & 1.54 & \multirow{2}{*}{-0.375} & \multirow{2}{*}{.708} & 1619 \\
\hline & $\mathrm{LC}$ & 1.55 & & & 381 \\
\hline \multirow{2}{*}{ Come Prepared } & Non-LC & 3.46 & \multirow{2}{*}{-3.253} & \multirow{2}{*}{.001} & 1619 \\
\hline & $\mathrm{LC}$ & 3.58 & & & 381 \\
\hline \multirow{2}{*}{ Class Participation } & Non-LC & 2.71 & \multirow{2}{*}{0.09} & \multirow{2}{*}{.928} & 1657 \\
\hline & $\mathrm{LC}$ & 2.7 & & & 392 \\
\hline \multirow{2}{*}{ Satisfied with Major } & Non-LC & 0.8 & \multirow{2}{*}{-2.224} & \multirow{2}{*}{.026} & 1649 \\
\hline & $\mathrm{LC}$ & 0.85 & & & 392 \\
\hline \multirow{2}{*}{ Social Fit } & Non-LC & 3.78 & \multirow{2}{*}{-5.7} & \multirow{2}{*}{.000} & 1619 \\
\hline & $\mathrm{LC}$ & 4.07 & & & 381 \\
\hline \multirow{2}{*}{ Academic Fit } & Non-LC & 4.06 & \multirow{2}{*}{-2.753} & 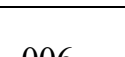 & 1634 \\
\hline & $\mathrm{LC}$ & 4.18 & & .006 & 387 \\
\hline Student Cluh & Non-LC & 0.33 & -1089 & 000 & 1668 \\
\hline Student Club & $\mathrm{LC}$ & 0.62 & -10.89 & .000 & 395 \\
\hline Studv with Students & Non-LC & 1.93 & 7077 & 000 & 1634 \\
\hline Study with students & $\mathrm{LC}$ & 2.34 & -1.911 & .000 & 387 \\
\hline Unsatisfactory Grade Letters & Non-LC & 0.59 & & 002 & 1668 \\
\hline Received & $\mathrm{LC}$ & 0.73 & -3.058 & .002 & 395 \\
\hline
\end{tabular}

Next, mediation analyses were conducted to explore possible mechanisms through which learning communities work and to test hypotheses 2 and 3. Judge, et al. (2001) suggest that the attitude to behavior link is strongest when the two are specific and matched to each other. The variables chosen for the mediation analyses meet these criteria. For hypothesis 2 perceived social fit precedes being a member of a student club. Deciding whether or not to join a student club should not be informed by academic focused attitudes and is the most social-specific behavior in the survey. The same logic was used to select studying with students outside of class as the dependent variable in hypothesis 3. Students can engage in this behavior of their own volition (as opposed to engaging in the classroom where participation may be graded). Being a member of a student club or organization and studying with students outside of the classroom are the survey items most related to perceived social and academic fit, respectively, and were thus used to test hypotheses 2 and 3.

Baron and Kenny (1986) provide steps for testing for mediation. The first step is to ensure that the antecedent variable (in both cases this is being a member of a learning community) is significantly related to the outcome 
variable. Correlational analyses found that being in a learning community was significantly correlated with both being a member of a student club or organization $(\mathrm{r}=.23, \mathrm{p}<.01)$ and studying with other students outside of class $(\mathrm{r}=.17, \mathrm{p}<.01)$. These correlations among focal variables satisfy the first step from Baron and Kenny (1986).

The next step is to ensure a significant relationship between the antecedent variable and the mediating variable. Correlational analyses supported this step; being in a learning community predicts perceived social fit $(\mathrm{r}=.12, \mathrm{p}<.01)$ and perceived academic fit $(\mathrm{r}=.06, \mathrm{p}<.01)$.

The next step is to test for a relationship between the mediator and the outcome variable holding the antecedent variable constant. Because being a member of a student club or organization is a dichotomous variable, logistic regression is used to test hypothesis 2 (MacKinnon \& Dwyer, 1993). In Table 2 (where the outcome variable is being a member of a student club) perceived social fit predicts being a member of a student club above and beyond being in a learning community $(B=.385, \mathrm{p}<.001)$. In Table 3 (where studying with students outside of class is the outcome variable) academic fit predicts studying with students above and beyond being in a learning community ( $b=.102$, $\mathrm{p}<.001)$. Together, Tables 2 and 3 reveal support for this step.

Table 2. Logistic mediation analysis for predictors of student club membership

\begin{tabular}{llllll}
\hline Model & Predictor & B & SE B & Wald & Odds Ratio \\
\hline Step 1 & LC & $1.19^{*}$ & .116 & 105.59 & 3.29 \\
& Constant & $-.701^{*}$ & .052 & 181.78 & .496 \\
& Model X ${ }^{2}(d f)$ & $109.55(1)^{*}$ & & & \\
\hline Step 2 & LC & $1.10^{*}$ & .120 & 84.46 & 3.00 \\
& Social Fit & $.385^{*}$ & .054 & 50.00 & 1.47 \\
& Constant & $-2.18^{*}$ & .219 & 99.50 & .112 \\
& Model X $(d f)$ & $156.80(2)^{*}$ & & & \\
\hline
\end{tabular}

Note. $\mathrm{N}=2063 . *$ denotes values at $\mathrm{p}<.001 . \mathrm{LC}=$ Learning Community.

Table 3. Mediation analysis for predictors of studying with students

\begin{tabular}{|c|c|c|c|c|c|}
\hline Criterion & & $b$ & s.e. & $R^{2}$ & $\Delta R^{2}$ \\
\hline \multirow[t]{3}{*}{ Academic Fit } & & & & $.004 *$ & .00 \\
\hline & (Intercept) & $4.06^{* *}$ & 0.02 & & \\
\hline & Learning Community & $.122 *$ & 0.04 & & \\
\hline \multicolumn{6}{|c|}{ Study with Students } \\
\hline \multirow[t]{3}{*}{ Step 1} & & & & $.031 * *$ & .00 \\
\hline & (Intercept) & $1.92 * *$ & 0.02 & & \\
\hline & Learning Community & $.409 * *$ & 0.05 & & \\
\hline \multirow[t]{4}{*}{ Step 2} & & & & $.038 * *$ & $.008 * *$ \\
\hline & (Intercept) & $1.51 * *$ & 0.11 & & \\
\hline & Learning Community & $.396^{* *}$ & 0.05 & & \\
\hline & Academic Fit & $.102 * *$ & 0.03 & & \\
\hline
\end{tabular}

Note. $\mathrm{N}=2063 . *$ denotes values at $\mathrm{p}<.01 ; * *$ denotes values at $\mathrm{p}<.001 ; b=$ unstandardized beta.

The final step for testing for full mediation is to compare the beta weights associated with the antecedent variable with and without the mediating variable entered. If full mediation is occurring then the antecedent variable should 
drop to non-significance from zero when the mediating variable is entered (Baron \& Kenny, 1986). In both cases the coefficients drop in value yet remain significant. These findings suggest partial mediation because the direct effect from the antecedent to the outcome variable remains significant. If the indirect effect passing through the mediator is significant as well then partial mediation is supported. A Sobel test is needed to test for the significance of an indirect effect (Sobel, 1982). A Sobel test works by finding the difference between the direct and indirect effect, its corresponding standard error, and applying a z-score to it. If the z-score associated with the indirect effect is greater than 1.96 (or less than -1.96) then the indirect effect is significant at $p<.05$. In the case of predicting student club membership the Sobel test estimate is significant $(Z=4.45, \mathrm{p}<.001)$. In the case of predicting studying with other students the Sobel test estimate is also significant $(Z=2.26, p<.05)$. Thus partial mediation is supported in both cases and hypotheses 2 and 3 are partially supported.

\section{Discussion}

Findings based on two years of student data generally support the effectiveness of learning communities at this university. Learning community students are more likely to report positive academic and social attitudes and behaviors when compared against their non-learning community peers. According to Astin (1993) learning communities promote interaction among faculty and students. The learning communities at this university are no exception. Students work together on school projects, engage in service-learning activities, and meet with faculty and staff supporting the learning community. This study found that these interactions meant that learning community students were more likely to know who their academic advisor is and to have received feedback on their performance from faculty and staff. Further, this study found that student engagement is a fruitful avenue for affecting student attitudes and ultimately behaviors, as reported by previous research (e.g., Barron, et al., 2009; Buch \& Spaudling, 2008). Learning community students shared positive attitudes of social fit and academic fit, and also reported engaging in more positive social and academic behaviors, including meeting with faculty members outside of class, coming to class prepared, studying with other students, and joining a student club or organization.

Both mediation models proposed in this study were partially supported. These findings support the idea that student behaviors are informed by student attitudes and the attitude to behavior link in general (Eagley \& Chaiken, 1993; Judge, et al., 2001; Kraus, 1995). It appears that learning communities foster shared attitudes about academic and social issues. Beyond these attitudes being shared, they are more positive than their non-learning community peers. Thus, these findings support the attitude to behavior relationship as the theoretical mechanism by which learning communities affect student outcomes.

The question remains of why the mediated models were only partially supported. Kraus (1995) argues that the relationship between an attitude and its corresponding behavior is strengthened when both the attitude and behaviors are made more specific. His meta-analytic findings support this notion (Kraus, 1995). For example, instead of asking about social fit to predict joining student clubs or organizations, a better predictor would be asking students about their attitudes concerning joining a student club or organization. Pointedly asking about specific attitudes increases their predictive power with their corresponding behaviors (Judge, et al., 2001).

As with most studies, this paper has limitations. The data are cross-sectional thus causality cannot be assumed. However, theory supports the formation of attitudes before engaging in corresponding behaviors (Eagley \& Chaiken, 1993). Further, students are placed in learning communities before the start of their first year on campus. Thus, it is unlikely that attitudes about university-related issues are formed (and shared) by learning community students before they enter the learning community. Overall it appears that being a member of a learning community supports and promotes important student attitudes and self-reported behaviors.

Future research in learning communities should focus on the attitude to behavior relationship and make sure to account for affective and cognitive consistency. Attitudes are theorized to be made up of two components- one affective and one cognitive (Millar \& Tesser, 1986). The affective component invokes emotional judgments about an attitudinal object; the cognitive component invokes logical judgments about an object. When the two are in disagreement then the corresponding behavior is far less likely to occur than when they are in agreement. In the previous example, this would mean asking students if joining a student club or organization sounds fun (affective) and if joining a student club or organization would be a smart move (cognitive). Recent research on attitudes suggests that when affective and cognitive components of an attitude are aligned then the corresponding behavior is much more likely to occur (Schleicher, Watt, \& Greguras, 2004). Controlling for this would likely increase the strength of the relationship between learning community student attitudes and behaviors to their true relationship. Attitude specificity, as suggested by Kraus (1995) should be another focus of future research. Future attempts at linking student attitudes to behaviors should make sure to account for how specific the attitude and its corresponding 
behavior are. More specific items will lead to stronger attitude to behavior relationships. Student behavior prediction is important both for academicians and practitioners at a university.

Finally, future research in learning communities should make sure to measure specific forms of student engagement. Using involvement theory, student engagement leads to academic and social outcomes (through attitudes and behaviors); however, the type of engagement is unclear. Perhaps interaction with faculty is more important than interaction with staff, advisors, or other students. Or, more likely, different types of interaction lead to different attitudes which then inform student behaviors.

\section{Conclusion}

The results of this study support the effectiveness of learning communities at this university, and by implication, the interaction and engagement approach taken by the learning communities. Astin's involvement theory has shown to be robust enough to explain the varying paths of influence between being in a learning community and increased student outcomes. Learning communities increase student engagement through increased faculty and student interaction (Astin, 1993). This increased interaction leads to increased student engagement (Taylor, 2004). The engagement fosters shared attitudes about social and academic outcomes as seen by the significant differences between learning community and non-learning community students in this study. These shared and significantly different attitudes of students within learning communities lead to increased academic and social behaviors. It is likely that these academic and social behaviors are linked to the favorable outcomes of academic success reported in other studies on learning communities (Buch \& Spaulding, 2008; Foster, 2005).

Learning community research is beginning to explore the causal links that tie being in a learning community to superior student outcomes. The current study adds to the literature by using existing theory on attitudes and behaviors and conceptually tying it to student engagement and involvement. It appears that engagement, involvement, and student interaction are related to student success outcomes via shared student attitudes and behaviors. Learning communities provide an effective vehicle for creating opportunities for students to interact with faculty, staff, and each other.

\section{References}

Astin, A. W. (1984). Student involvement: A developmental theory for higher education. Journal of College Student Personnel, 25, 297-808.

Astin, A. W. (1985). Achieving educational excellence. San Francisco: Jossey-Bass.

Astin, A. W. (1993). What matters in college?: Four critical years revisited. San Francisco: Jossey-Bass.

Baron, R. M., \& Kenny, D. A. (1986). The moderator-mediator variable distinction in social psychological research: Conceptual, strategic and statistical considerations. Journal of Personality and Social Psychology, 51, 1173-1182. http://dx.doi.org/10.1037/0022-3514.51.6.1173

Barron, K. E., Buch, K., Andre, J. T., \& Spaulding, S. (2009). Learning communities as an innovative beginning to the psychology major: A tale of two campuses. In Dunn, D. S., Beins, B. C., McCarthy, M. A., \& Hill, G. W., IV (Eds.). (2009). Best practices for teaching beginnings \& endings in the psychology major. Oxford: University Press.

Buch, K., \& Spaulding, S. (2008). A longitudinal assessment of an initial cohort in a psychology learning community. Teaching of Psychology 35, 1-5. http://dx.doi.org/10.1080/00986280802181582

Eagly, A. H., \& Chaiken, S. (1993). The psychology of attitudes. Fort Worth, TX: Harcourt Brace Jovanovich.

Hofmann, D. A., Morgeson, F. P., \& Gerras, S. (2003). Climate as a moderator of the relationship between LMX and content specific citizenship: Safety climate as an exemplar. Journal of Applied Psychology, 88, 170-178. http://dx.doi.org/10.1037/0021-9010.88.1.170

Judge, T. A., Thoresen, C. J., Bono, J. E., \& Patton, G. K. (2001). The job satisfaction job performance relationship: A qualitative and quantitative review. Psychological Bulletin, 127, 376-407. http://dx.doi.org10.1037/0033-2909.127.3.376

Kraus, S. J. (1995). Attitudes and the prediction of behavior: A meta-analysis of the empirical literature. Personality and Social Psychology Bulletin, 21, 58-75. http://dx.doi.org10.1177/0146167295211007

Lenning, O. T., \& Ebbers, L. H., (1999). The powerful potential of learning communities. ASHE-ERIC Higher Education Report Volume 26, Number 6. 
Millar, M.G., \& Tesser, A. (1986). Effects of affective and cognitive focus on the attitude-behavior relation. Journal of Personality and Social Psychology, 51, 270-276. http://dx.doi.org/10.1037/0022-3514.51.2.270

Millar, M.G., \& Tesser, A. (1989). The effects of affective-cognitive consistency and thought on the attitude-behavior relation. Journal of Experimental Social Psychology, 25, 189-202. http://dx.doi.org/10.1016/0022-1031(89)90012-7

Schleicher, D. J., Watt, J. D., \& Greguras, G. J. (2004). Reexamining the job satisfaction-performance relationship: The complexity of attitudes. Journal of Applied Psychology, 89, 165-177. http://dx.doi.org/10.1037/0021-9010.89.1.165

Taylor, K. (2004). Learning community research and assessment: What we know now. Washington, DC: American Association for Higher Education.

Tinto, V. (2000). What we have learned about the impact of learning communities on students. Assessment Update, $12(2), 1-2,12$.

Zhao, C. M., \& Kuh, G. D. (2004). Adding value: Learning communities and student engagement. Research in Higher Education, 45, 115-138. http://dx.doi.org/10.1023/B:RIHE.0000015692.88534.de

Zohar, D. \& Luria, G. (2005). A multilevel model of safety climate: Cross-level relationships between organizations and group-level climates. Journal of Applied Psychology, 89, 567-577.

Zohar, D. (2000). A group-level model of safety climate: Testing the effect of group climate on microaccidents in manufacturing jobs. Journal of Applied Psychology, 85, 587-596. http://dx.doi.org/10.1037/0021-9010.85.4.587 